\title{
Online teaching in COVID-19 times. Student satisfaction and analysis of their academic performance
}

\author{
Beatriz Jiménez-Parra, Daniel Alonso-Martínez, Laura Cabeza-García, Nuria \\ González-Álvarez
}

Department of Management and Business Economics, Universidad de León, Spain.

\begin{abstract}
Online teaching has grown exponentially as a result of COVID-19. Universities and teaching institutions the world over have had to adapt their curricula to this new teaching and learning model. The main goal of this study is to analyse various teaching methodologies used on a sample of university students to analyse their effectiveness in terms of satisfaction, competencies and academic performance. The results suggest that methodologies that include greater student-teacher interaction or the use of videoconferencing for classes and problem-solving help to raise student satisfaction. Students also positively assess online teaching as it allows them to acquire new competencies and even to identify business opportunities. The online evaluation method used also seems to have been appropriate, as it led students to obtain better grades than in face-to-face teaching contexts. The study offers several implications for university teachers of Social Sciences who wish to adopt this type of teaching method.
\end{abstract}

Keywords: Online teaching; online evaluation; assessment/satisfaction; academic performance. 


\section{Introduction}

The process of digital transformation and the consolidation of online teaching that has been under way over recent years took off as a result of the COVID-19 pandemic. Some authors (such as Cifuentes-Faura, 2020) claim that the education sector needs to re-invent itself in this uncertain context and stress that one of the greatest challenges is to hold the attention of students and improve their competencies. However, other authors such as Sangrà (2020) claim that the challenge is to adapt and to include in online teaching certain aspects of faceto-face teaching such as personalised attention, greater connection with students and effective verbal communication.

Even though there is extensive debate on what is meant by online teaching or $e$-learning, it can be defined as the use of new multimedia technologies and the Internet to improve the quality of learning by facilitating access to resources and services as well as remote exchanges and collaboration (European Commission, 2001). The $e$-learning sector is expected to surpass 243 billion US dollars by 2022 worldwide (Duffin, 2020). Over recent years, universities and educational institutions all over the world have fostered online teaching with the aim of adapting to the new reality that recommends avoiding physical contact and reconsidering the way in which the learning and teaching process takes place (Govindarajan and Srivastava, 2020). A teaching model has thus been introduced involving various methods that range from more or less hybrid teaching to purely virtual teaching. All this has required greater resources for improving and introducing new educational technologies and for training teachers and students on how to gain greatest benefit from them (Li and Lalani, 2020).

Traditionally, the literature suggested that it was necessary to include certain innovative aspects, often related to the use of technology, to make face-to-face teaching more attractive, to improve students' satisfaction and performance or to facilitate learning (Bennett et al., 2018). At the same time, online teaching was beginning to become consolidated, especially in higher education. The key aspects on which work needed to be done were: to develop and introduce new tools allowing for greater interaction with students, to offer evaluation methods suited to this context and to guarantee follow-up of the learning process (Dumford and Miller, 2018). But 2020 amounted to a turning-point, requiring teaching at all levels and practically throughout the world to be given online. The context changed completely and the main priority was to meet the needs arising for institutions and for teachers and students. All this aimed, first, to guarantee that students could still acquire and improve their competencies in the subjects studied and, second, to ensure that their motivation and/or satisfaction were as great as possible (Sangrà, 2020).

In general, online teaching allows students to access information asynchronously, at any time and in any place, using electronic tools, methodologies and devices. This type of learning 
affords great flexibility for organising and planning study times and independent work (Smedley, 2010). But this process of teaching and learning can also take place synchronously. Online teaching has become a tool that facilitates and enables interaction in real time for students and teachers (Beldarrain, 2006). In addition, in this context, new technologies have played and continue to play a key role (McGreal and Elliot, 2011), to the extent that a large number of tools have appeared over recent years to facilitate such remote teaching (Huda et al., 2018). There are now platforms and applications (Moodle, Zoom, Google Meet, etc.) that allow groups of students and teachers to connect and interact in real time, making the teaching and learning process increasingly similar to how it works in face-to-face situations.

This study has a dual goal: on the one hand, to find out how a sample of university students on business-related courses assess various online methodologies and evaluation systems (in terms of satisfaction and development of competencies); and, on the other, to compare academic performance resulting from online teaching with that from face-to-face teaching. It is structured as follows. We first describe the sample used, and the design of the research. We then present and discuss the main results obtained and, finally, draw some conclusions.

\section{Teaching experience}

\subsection{Sample and research design}

This teaching experience took place during the second semester of the 2019/2020 academic year. It considered the students of a Spanish university on various degree courses within the Faculty of Economic and Business Science (169 students) and a Master's degree course (13 students) in order to know their assessment and how they adapted to the online context. A total of 182 students participated. The sample eventually used comprised 124 students, that is, $68.1 \%$ of the total. The responses obtained in each study course can be broken down as follows: Degree in Business Administration and Management (BAM) (51.61\% of students enrolled on the course), Degree in International Commerce (IC) (54.05\% of students enrolled on the course), Degree in Marketing and Market Research (MMR) (77.5\% of students enrolled on the course), Degree in Tourism (TOURISM) (93.33\% of students enrolled on the course), and the Inter-University Master's Course on Research in Business Administration and Economics (MASTER) (100\% of students enrolled on the course).

The information was collected by using an anonymous, online questionnaire during the last few weeks of the semester, specifically between 25 May and 15 June $2020.70 .16 \%$ of the responses received were from women. Also, $46 \%$ of the students who filled in the questionnaire stated that they had professional experience, and the average age was 23 . Each teacher explained to their students the purpose of the questionnaire and briefly explained it. The questionnaire comprised an initial section on methodology (6 questions) and teaching evaluation ( 3 questions) and a second section for a general assessment ( 6 questions). Before 
the final questionnaire was sent out to the students, it was pre-tested with other university students to identify any shortcomings (items not clearly expressed, aspects difficult to understand, inappropriate order of questions, etc.). In addition, academic performance in the subjects considered was analysed.

\subsection{Results}

\subsubsection{General assessment: teaching methodology and online evaluation}

Before the students' assessment can be presented, it should be mentioned that in the subjects covered on the degree courses in BM, IC and MMR the teachers chose to provided complete, adapted materials to the students, with complementary reading and explanatory videos for the theoretical classes and detailed feedback/solutions in writing for practical work. In the case of the Master's course and the degree course in Tourism, classes were given by videoconference for both theory and practice. In all cases, the timetable was adhered to for all activities and explanations. Any questions asked by students were answered via email and videoconference in general and, in the case of BAM and MMR, a Moodle forum was also created.

One of the questions asked in the questionnaire regarding the teaching methodology was whether the students considered the teacher's adaptation to the new online context appropriate for facilitating learning. $78.23 \%$ of students answered affirmatively, while $16.17 \%$ stated it could have been better, suggesting above all that classes via videoconference could be increased or content could be better adapted to the new online context. Most of the students also considered that interaction was similar to the period prior to lockdown with both their teachers $(72.58 \%)$ and their classmates (58.06\%). In spite of this largely positive assessment of the teacher's adaptation and of interaction, most of the students found that online learning was less interesting than face-to-face learning (66.94\% against $22.06 \%$ ).

The questionnaire also included questions to compare online and face-to-face teaching. A majority of the students $(53.23 \%)$ considered that the online teaching was not more difficult to follow than face-to-face teaching, while $16.94 \%$ stated they had found difficulties, and $29.34 \%$ had only occasionally had problems. The main problems identified were difficulties for understanding topics $(41.6 \%)$ or an excessive workload $(14.58 \%)$. Regarding the students' academic performance, $50 \%$ considered that their results would have been similar if they had received face-to-face teaching, $40.32 \%$ considered they would have been better, and $9.68 \%$ considered they would have been worse. The students also considered that the knowledge obtained is similar in online and face-to-face teaching (51.61\%), and $14.52 \%$ even considered it had been better online.

Regarding the evaluation method used by teachers in the new context, in all subjects partial examinations were given online and in multiple-choice format. For the MMR and Master's 
courses, the weight of all the components in the evaluation was kept the same and for the other subjects some slight adjustments were made. A large percentage of students $(84.68 \%)$ considered that the new method of evaluation had been appropriate, as opposed to only $2.42 \%$ who considered it was not and $12.90 \%$ who believed it could have been better. The main suggestions were to increase the weight of continuous assessment and replace exams with practical work.

Finally, with regard to the general assessment section, most of the students were very $(16.94 \%)$ or fairly $(72.26 \%)$ satisfied with the online learning received. Moreover, $50.81 \%$ stated that the online teaching had enabled them to acquire new competencies or skills such as using ICT and improving their capacity for self-management. This type of teaching also allowed the students to discover new business opportunities, as stated by $18.55 \%$ of the students surveyed, and to identify potential uses of ICT in a range of settings $(91.67 \%$ of the students who replied affirmatively to this question); regarding this last question, most of the students $(83.33 \%)$ proposed that existing business lines could be offered in a virtual context.

\subsubsection{Association between teaching methodology, evaluation and satisfaction with the online} learning

Considering that in general students' assessment/satisfaction was positive, an analysis was performed to see if there was an association between students' satisfaction (high/low) with the online learning (alternatively, we also considered if the students had developed new skills or not) and the way in which the online teaching was given, questions were answered and the evaluation system was used. We also explored the possibility of a link between the degree of student satisfaction and their gender, age, course or prior professional experience. For this purpose, since the samples were not related and since all variables considered are qualitative, a Chi-squared independence test was used, except for the case of age, which is a continuous variable so the Mann Whitney U test was used.

Our results suggest that there is a significant association between the teachers' adaptation to the new online context and student satisfaction. So, students are more satisfied the more the teacher's adaptation has been appropriate. In addition, we found a significant association between interaction with the teacher and student satisfaction, so greater or similar teacherstudent interaction leads to a greater degree of satisfaction. The students also related the evaluation method used in the context of online teaching with their satisfaction. The more the students considered the method and evaluation platforms to have been appropriate, the greater their satisfaction.

Conversely, the results show that there are no significant associations between the way in which the teacher taught the content or answered questions and student satisfaction. Similarly, student satisfaction does not seem to be related to interaction with classmates during lockdown. Regarding the relation between students' degree of satisfaction and their 
gender, age, course or prior professional experience, we only found significant differences in the latter, showing that students who had performed a professional activity were less satisfied.

On the other hand, the results do show that the acquisition of new skills is significantly associated with the way in which the teacher passed on the content. The students who stated they had acquired new skills had received knowledge from teaching videos, by solving case studies in writing and in detail and from classes via videoconference. However, the recommended reading and materials contributed to a lesser degree to the acquisition of competencies. The results also show a significant association between the way in which the teacher answered questions and the new competencies and skills acquired. The students whose questions were answered via videoconference or email stated they had acquired more competencies than those whose questions were answered via fora. In the same way, there is a significant association between interaction with the teachers and the skills acquired by students. The students who stated they had interacted more with the teacher declared that they had acquired more skills or competencies. Regarding the evaluation method, we also found an association with the skills or competencies acquired. Although both groups mostly stated that the teacher's evaluation method was appropriate, those who had acquired most competencies (in comparison with the rest) suggested more that it would be necessary to modify the evaluation method.

Finally, a significant association was also found between the competencies acquired and age, course and professional experience. The youngest students and those on courses in Tourism and MMR stated they had acquired more skills than those on the degree courses in BAM and CI or on the Master's course. It was also found that the students with professional experience acquired fewer new skills.

\subsubsection{Comparison of academic performance: online versus face-to-face teaching}

In order to compare the results obtained by students during the online teaching period with those during face-to-face teaching, we used the $t$ test for difference in means to compare average grades obtained in the subjects covered in this study during the 2019-2020 academic year with the mean of final grades for each subject during the three previous academic years. Considering that the final grade is the result of the student's learning and that it might be affected by the evaluation method used, the reference group in which there might have been least bias (same or similar content, same teacher, etc.), even if the teaching methodology and evaluation method had changed slightly, would be the students of each subject during previous years. Another aspect to be borne in mind which might affect the grade for the year being studied (apart from online teaching and evaluation) is whether such students are better or worse than those the previous year. To partly minimise this bias, it was decided to take the average grade from the previous three academic years for each subject. 
Although we have to be aware that other aspects may have an influence (e.g., the way of assessment or possible copying), the results show significant differences in all the final average grades for all subjects. In all cases, the differences were significant at $1 \%$ except for the 'Entrepreneurship' subject on the Master's course, in which the differences were at $10 \%$. It can therefore be concluded that, on average, the students enrolled on the subjects covered by this study obtained better grades during the online teaching period in comparison with the grades obtained during the three previous years of face-to-face teaching.

\section{Conclusions}

It can be concluded from the study that, in spite of the emergency situation resulting from COVID-19, in general, the teaching methodology used by teachers had been adapted well. Students gave a positive assessment to their online learning even though they find it less attractive than face-to-face learning. They consider that this type of learning has allowed them to acquire new ICT-related skills, such as the capacity for self-management or the identification of new business opportunities linked to a move to an online format for some existing businesses. Also, the online evaluation method used in some of the subjects included in the analysis seems to have been appropriate

However, in spite of this positive assessment, the students suggest some areas for improvement such as an increase in the number of classes given via videoconference and a better adaptation of materials to the online context to facilitate understanding of the subjects. Other important aspects mentioned are greater weight for continuous evaluation, and a more balanced workload for students. All these matters have important implications that should be taken into account by teachers so that they can enhance the learning and teaching process in online teaching contexts.

The main factors affecting student satisfaction are: adaptation of content to the online context, the method of student-teacher interaction and the evaluation method used. However, it seems that such satisfaction is not affected by either student-student interaction or the method adopted by the teacher to teach content or answer questions. This last factor does, however, affect students' acquisition of competencies, as do some personal factors (age, course and professional experience). Finally, we should stress that students' grades were not negatively affected by the change to online teaching because in all cases they rose significantly. This leads us to wonder if the evaluation method chosen, even if followed with the greatest possible rigour, perhaps does not accurately capture the knowledge acquired by students.

This study has certain limitations: the descriptive nature of the study, its specific context in that it considers a single Spanish university and subjects linked specifically to business as well as that most of the sample population were women. It therefore seems necessary to carry 
out further studies to help improve the online or hybrid teaching and learning process that is currently being used in a large part of the Spanish university system.

\section{References}

Beldarrain, Y. (2006). Distance education trends: Integrating new technologies to foster student interaction and collaboration. Distance Education, 27(2), 139-153. doi:10.1080/01587910600789498.

Bennett, S., Lockyer, L., \& Agostinho, S. (2018). Towards sustainable technology-enhanced innovation in higher education: Advancing learning design by understanding and supporting teacher design practice. British Journal of Educational Technology, 49(6), 1014-1026. doi:10.1111/bjet.12683.

Cifuentes-Faura, J. (2020). Docencia online y Covid-19: La necesidad de reinventarse. Revista de Estilos de Aprendizaje, 13(Especial), 115-127. Retrieved from http://revistaestilosdeaprendizaje.com/article/view/2149.

Duffin, E. (2020, February 6). E-learning and digital education. Statistics \& Facts. Statista. Retrieved from https://www-statista-com.

Dumford, A.D., \& Miller, A.L. (2018). Online learning in higher education: Exploring advantages and disadvantages for engagement. Journal of Computing in Higher Education, 30, 452-465. doi:10.1007/s12528-018-9179-z.

European Commission. (2001). The e-learning action plan: Designing tomorrow's education. Communication from the Commission to the Council and the European Parliament (COM (2001) 172 Final). Brussels: Author. Retrieved from lex.europa.eu/LexUriServ/LexUriServ.do?uri=COM:2001:0172:FIN:EN:PDF

Huda, M., Maseleno, A., Atmotiyoso, P., Siregar, M., Ahmad, R., Jasmi, K., \& Muhamad, N. (2018). Big data emerging technology: Insights into innovative environmental for online learning resources. International Journal of Emerging Technology in Learning, 13(1), 23-36.

Li, C., \& Lalani, F. (2020, May 20). La pandemia COVID-19 ha cambiado la educación para siempre. Así es como se ve el distanciamiento social en escuelas de todo el mundo. World Economic Forum. Retrieved from https:/es.weforum.org/agenda/2020/05/la-pandemiacovid-19-ha-cambiado-la-educacion-para-siempre-asi-es-como/.

McGreal, R., \& Elliott, M. (2011). Technologies of online learning (e-learning). In T. Anderson (Ed.), The theory and practice of online learning (pp. 144-166). Edmonton: Au Press.

Sangrà, A. (2020). Decálogo para la Mejora de la Docencia Online. Barcelona: Editorial UOC.

Smedley, J.K. (2010). Modelling the impact of knowledge management using technology. OR Insight, 23, 233-250. doi:10.1057/ori.2010.11. 